\title{
Baboons of the Amboseli Basin: Demographic Stability and Change
}

\author{
A. Samuels ${ }^{1}$ and J. Altmann ${ }^{1,2}$ \\ Received April 10, 1990; revised July 26, 1990
}

$A$ cross-sectional demographic analysis of the entire baboon population of the Amboseli basin of southern Kenya was undertaken to complement the longitudinal, intensive studies of a subpopulation. The present survey documented the extent and persistence of the influx of anubis baboons into the predominantly cynocephalus community and provided another example of the nonrundom dispersal patterns of cercopithecine males. In addition, the survey confirmed continued demographic stability of the basinwide baboon population and even growth in groups that had access to better feeding conditions, despite decline of the baboons' preferred habitat and expansion of human activities into wildlife areas. Conflicts with activities of humans, ho:vever, indicate that the present well-being of the Amboseli baboon population may be short-lived.

KEY WORDS: baboons; demography; food provisioning; human-wildlife conflict.

\section{INTRODUCTION}

Research on the demography and behavioral ecology of savannah baboons in Amboseli, Kenya, has produced detailed, longitudinal data for individually identified animals of several groups (Walters, 1980; Hausfater et al., 1982; Altmann et al., 1988). Such long-term, intensive study of a subpopulation is essential for understanding the mechanisms and details of demographic structure. Because behavioral interactions, genetic exchange, disease transmission, and other processes occur over a broader geographic

${ }^{1}$ Department of Conservation Biology, Chicago Zoological Society, Brookfield, Illinois 60513, and Institute of Primate Research, National Museums of Kenya, Nairobi, Kenya.

${ }^{2}$ Department of Ecology and Evolution, University of Chicago, Chicago, Hlinois 60637. 
range, information about the larger population of which the selected groups are a part is equally important. In only a few studies of nonhuman primates has it been possible to provide demographic data both within groups and across a whole population (Dittus, 1977; Harcourt et al., 1980, 1981; Goodall, 1986). Here we present a cross-sectional demographic analysis for the entire baboon population of the Amboseli basin to complement the longitudinal, intensive studies of the subpopulation.

The goal of the present investigation was to determine whether the recent stability and demographic characteristics of the central basin subpopulation (Altmann et al., 1985) were representative of the larger population. In particular, we sought (1) to identify characteristics of groups within the population that are demographically more successful; (2) to obtain more information on the recent migration of olive baboons into the predominantly yellow baboon population (Samuels and Altmann, 1986); and (3) to expand our measurement of the dispersal area of males.

\section{Amboseli and Its Baboon Population}

The Amboseli basin is an area of semiarid savannah in southern Kenya, described in detail by Western (1973), Western and Sindiyo (1972), and Western and van Praet (1973). The basin is the site of an extinct Pleistocene lake, defined by natural physical boundaries. Within the basin, Amboseli National Park, established in 1977, is a $390-\mathrm{km}^{2}$ area containing most of the basin's permanent natural water sources in the form of perennial springs and swamps derived from runoff from Mt. Kilimanjaro.

Wildlife concentrate in the basin during the dry season because of the availability of good late-season forage and permanent water. During the rains, wildebeest, zebra, and other migratory species move into the highlands surrounding the basin, where they can drink from temporary rainpools. Although the basin's natural boundaries are not a barrier to these migratory species, a semiisolated population of savannah baboons resides therein.

Dispersal of the Amboseli baboons out of the basin is limited by ecological barriers (Fig. 1). To the north, Eremito Ridge marks the edge of the ancient lake and the beginning of an extensive waterless scrub plain; the nearest baboon population to the north is more than $80 \mathrm{~km}$ away, in the Simba-Kiboko region. To the west, a seasonally flooding relic of the Pleistocene lake separates Namanga baboons from the Amboseli population by $45 \mathrm{~km}$. To the south, mixing between Mt. Kilimanjaro and Amboseli baboon populations is probably infrequent or of recent origin (Samuels and Altmann, 1986). Dispersal of baboons to and from the basin occurs primarily in the east, where a range of hills presents no obstacle to baboon movements. 


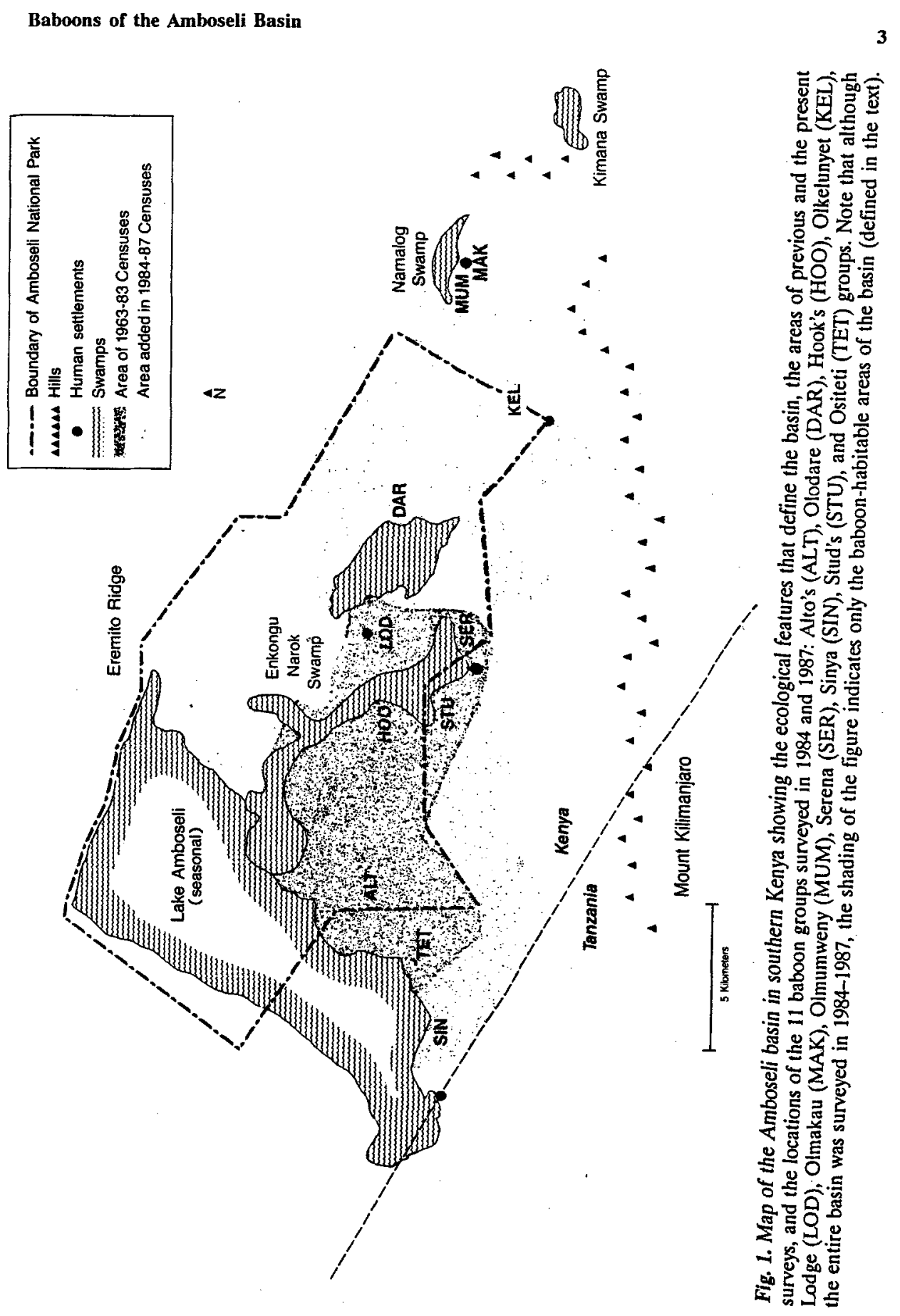




\section{METHODS}

Repeated censuses of the baboons in the central western portion of the Amboseli basin, an area of $68.4 \mathrm{~km}^{2}$, from Enkongu Narok Swamp to Nairabala Hill (Fig. 1), were conducted from 1963 to 1983 (Altmann et al., 1985). The present survey encompassed the entire basin, an area of approximately $600 \mathrm{~km}^{2}$ (Western, 1973), thus extending the area of the original surveys to include the Sinya area at the Kenya-Tanzania border to the west and the rest of Amboseli National Park and Namalog Swamp to the east. The eastern boundary of the survey is somewhat arbitrary because baboons are continuous from Namalog, within the basin, to Kimana and farther east, outside of the basin. Baboons living in the hills were not included in the present survey, because they are not primary inhabitants of the basin and because much effort would have been required to census these unhabituated and wary baboons in rough terrain.

The basinwide survey was initiated during the short rains of 1984 (November-December), and an additional group was located during the long rains of March 1985. During the dry season of 1987 (June-August), all but the three easternmost groups were censused again. The eastern groups (KEL, MAK, MUM) could not be recensused in 1987 because the expansion of agricultural land into wildlife habitat resulted in conflict between farmers and baboons in the Namalog area.

The censusing technique is described by Altmann and Altmann (1970). Briefly, baboons were visually identified by age and sex as they moved past an arbitrarily chosen counting point in a progression across an open area. Censuses were repeated several times on each group.

The expertise necessary for conducting a basinwide survey and for identifying age/sex classes was gained through regular systematic evaluations of the physical developmental characteristics of immature baboons of known age in the primary study groups and from periodic censusing of groups adjacent to the primary study groups. All members of the primary study groups (ALT and HOO, plus LOD in 1987; see Fig. 1) were individually known as subjects of longitudinal behavioral, ecological, and demographic research. Monitoring the movements and interactions of primary study groups provided us with information on the whereabouts of other groups in the basin. In addition, unfamiliar groups were located by monitoring sleeping or watering places and by consulting Park rangers, researchers, and local Maasai. We are confident that all groups were located because of the intensity and duration of our search and the limited distribution of baboon sleeping and watering sites in Amboseli. 


\section{Demographic Categorization}

We recorded the age of all individuals and the sex of all adults. Each adult male was scrutinized to determine whether he was one of those known to have emigrated from the primary study groups during 1982-1987. Developmental classes were defined and distinguished as by Altmann et al. (1981), with the exceptions that the two infant classes and two juvenile classes were each combined into single classes: "infant/yearling" and "juvenile."

Individuals for which complete information was not attainable were classified according to the class distribution of individuals in those baboon groups for which there were no unknown individuals. This method resulted in some underestimation of intergroup variability, but the proportion of unclassified individuals was small. In the 1984 survey, only $2.5 \%$ of individuals were of unknown age/sex class; their classification was based upon complete information obtained for six groups. In 1987, complete information was obtained for all individuals.

Because baboons are a relatively polygynous species in which females typically outnumber males among sexually mature animals (Altmann and Altmann, 1970), we tested for equal sex ratios among adults. Because declining populations of macaques, primates with life stages similar to baboons, are reported to have a deficit of immature animals (Southwick and Siddiqi, 1976, 1977), we tested for equal prevalence of immature and mature animals. Comparisons of demographic classes are reported as ratios to conform to the literature, e.g., a group comprised of 1.0 female per male contains equal numbers of females and males.

For evaluation of the demographic condition of a group. Altmann et al. (1985) concluded that "an older juvenile class that is one-half the size of the adult female class is one that would provide replacement but not growth" in a baboon population with rates of maturation and adult female mortality as found in ALT (Altmann, 1980, unpublished data). However, recent data on LOD (J. Altmann et al., unpublished) and on other semiprovisioned cercopithecines (reviewed by Altmann, 1986; Fa and Southwick, 1988; Asquith, 1989) confirm that maturation is accelerated and adult mortality is reduced under conditions of food enrichment. Differences in these demographic parameters will change the size of the juvenile class that will be adequate for replacement and will serve as an indicator of demographic health. Consequently, to evaluate demographic condition in the absence of longitudinal data for each group in the present survey, we simply report actual adult female replacement in each of the primary study groups, representing three of the feeding conditions. 


\section{Taxonomic Categorization}

Savannah baboons have been designated separate species (Maples and McKern, 1967; Napier and Napier, 1967). Nonetheless, several types are able to interbreed and some taxonomists (Buettner-Janusch, 1966; Jolly and Brett, 1973) accord them subspecific status. The Amboseli baboon population consists primarily of yellow baboons, Papio cynocephalus or $P$. cynocephalus cynocephalus, hereafter referred to as yellow or cynocephalus. Beginning in 1982, olive baboons, $P$. anubis or $P$. cynocephalus anubis, hereafter referred to as olive or anubis, became a small but persistent component of the basin population. Evidence for a new or unstable cynocephalus-anubis hybrid zone in southwestern Amboseli is presented by Samuels and Altmann (1986).

During the survey of the Amboseli basin, each animal was scrutinized to determine its taxonomic type: among adults and juveniles, yellow baboons are visually distinct from olive baboons by coat color, facial characteristics, length of cheek and mantle hair, and body shape (Maples and McKern, 1967; Kingdon, 1974). We were unable to identify visually the taxonomic type of yearlings and infants.

Neighboring baboon populations to the south and west are anubis [Mt. Kilimanjaro (B. Oguya and D. Western, personal communications); Namanga (Maples and McKern, 1967; personal observation)]. The SimbaKiboko baboons to the north are cynocephalus-anubis hybrids (Maples and McKern, 1967). Baboons living in Kilmana and further east are cynocephalus (van Citters et al., 1967; Altmann and Altmann, 1970).

\section{Categorization of Feeding Condition}

Baboon groups of the Amboseli basin were classified according to feeding condition by a general assessment of the quality and distribution of food resources. Groups that fed entirely upon natural foods were further divided into "savannah groups" that range primarily in dry savannah areas and "swamp groups" that range primarily in lusher swamp regions. Other baboon groups obtained a significant portion of their diet from human foods in addition to natural foods. For groups classified as "garbage-feeding groups," provisioning occurred at the open garbage pits of tourist facilities, where discarded human foods were regularly available to baboons and other wildlife. Another form of provisioning occurred at the eastern edge of the basin, where the Amboseli Maasai are shifting their livelihood from nomadic pastoralism to sedentary agriculture and where land traditionally shared by wildlife and livestock is being converted to small farms. In these 
new agricultural areas, "crop-feeding groups" supplemented their diets with cultivated maize, onions, and tomatoes.

\section{Statistical Tests}

Testing was done against a binomial hypothesis of equiprobability $(p=q=0.50)$, using a significance level of 0.05 , two-tailed, to examine sex distribution among adults, proportion of immature animals, and changes in group size.

\section{RESULTS}

\section{Characteristics of the Amboseli Baboon Population in 1984}

A total of 11 baboon groups was found in the Amboseli basin in 1984 (Fig. 1). Six of them fed entirely upon natural foods: savannah groups $(n=$ 4)-ALT, KEL, SIN, and TET; and swamp groups $(n=2)-\mathrm{DAR}$ and HOO. Five groups supplemented their diet with human foods: garbagefeeding groups $(n=3)-$ LOD, SER, and STU; and crop-feeding groups $(n=2)-\mathrm{MAK}$ and MUM.

The density of the $476-479$ baboons of the basin was 1.15 baboons per $\mathrm{km}^{2}$ within the approximately $416 \mathrm{~km}^{2}$ of baboon-habitable land, loosely defined as areas of Acacia woodlands and permanent waterholes. Seven of the 11 groups, or 282-284 baboons, ranged partially or entirely within the boundaries of Amboseli National Park, while the far-western (SIN, TET) and far-eastern (MAK, MUM) groups were never observed within park boundaries. Within the $390-\mathrm{km}^{2}$ park, the density of baboons could have been as great as 0.73 baboon per $\mathrm{km}^{2}$; but the actual density at any time was probably lower because only four baboon groups (DAR, HOO, LOD, SER), or a total of 134-136 baboons, ranged primarily within park boundaries. At least half of the ranges of each of the other groups (ALT, KEL, STU) were outside of the park.

Group size varied from 17-18 to 77 individuals (Fig. 2). Median group size was 39 baboons: median size of each age/sex class was 7 adult males, 2 subadult males, 12 adult females, 9 juveniles, and 8 infants/yearlings.

Group composition varied from one multifemale/single-male group to multifemale/multimale groups and included one group in which the number of adult females was exceeded by the number of adult males (SIN; sex ratio $=0.93$ female per male). A significant number of groups had femalebiased adult sex ratios ( $n=11$ groups, $p=0.006)$; and overall, adult 

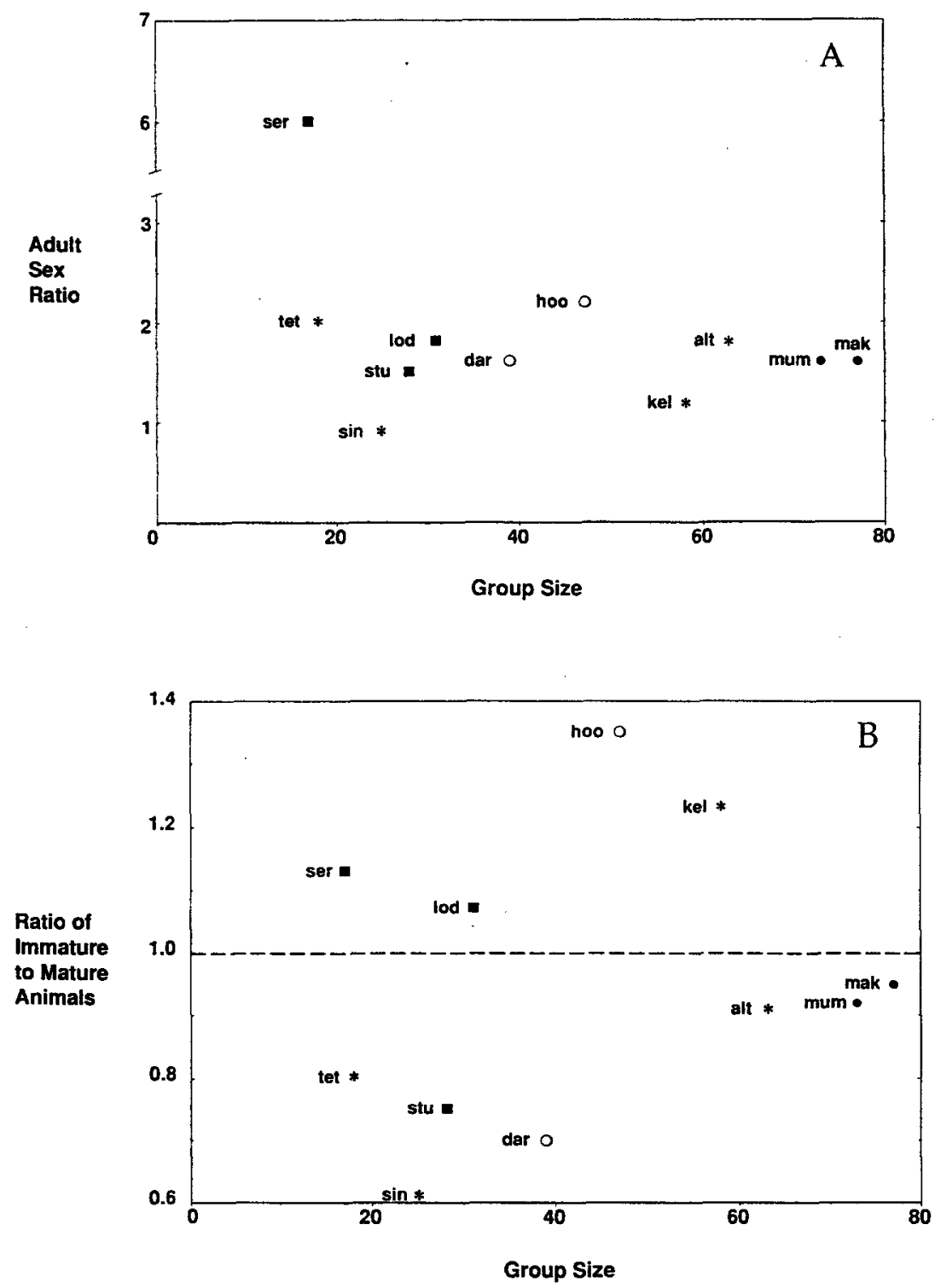

Fig. 2. The relationship in 1984 of group size to (A) the ratio of adult females to adult males and $(B)$ the ratio of immature to mature animals. Feeding conditions are indicated by asterisks for savannah groups, open circles for swamp groups, filled circles for crop-feeding groups, and filled squares for garbage-feeding groups. 
females significantly outnumbered adult males in the population (sex ratio of all groups pooled $=1.62$ females per male, $n=223$ adults, $p<0.001$ ). In only one group, however, did the number of females significantly differ from the number of males (SER; sex ratio $=6.0, n=7, p=0.016$; see Fig. 2A).

Adult sex ratio was unrelated to group size (Spearman rank correlation coefficient $r_{\mathrm{s}}=-0.116$, NS) but was related to feeding condition. Although savannah groups had a low combined adult sex ratio (1.42 females per male; $n=78$, NS), females significantly outnumbered males in cropfeeding groups (sex ratio $=1.57, n=70, p=.05$, swamp groups (sex ratio $=1.86, n=40, p=.038$ ), and garbage-feeding groups (sex ratio $=$ 2.0, $n=36, p=.028$ ).

Approximately half of the population consisted of sexually mature animals, i.e., adult and subadult males and postmenarcheal females; overall, the ratio of immature to mature animals was 0.95 . Group composition ranged from 0.61 to 1.35 immature to mature animals; but no group or feeding condition differed significantly from equal proportions of immature and mature members (see Fig. 2B).

\section{Presence of Olive Baboons}

More than $95 \%$ of juveniles and adults of the Amboseli baboon population in 1984 were yellow-type baboons. The remaining baboons (1517 of 380 juveniles and adults) were anubis in appearance and were found only in the three westernmost groups.

All anubis members of ALT and SIN were males. Two anubis males (one adult, one older juvenile), known to be immigrants, were present in $\mathrm{ALT}$, and five anubis males (three adults, one subadult, one older juvenile) were found in adjacent SIN.

Anubis females were present only in TET. More than half of the members of TET were anubis in appearance, including at least two juveniles and an least four of the six adult females. Two adult females could not be classified, because although they were yellow in coat color, the features of their faces, bodies, and tails were more anubis-like; they probably were hybrids.

\section{Changes in the Characteristics of the Amboseli Baboon Population, 1984 to 1987}

Eight of the 11 baboon groups, a total of 325-327 baboons, were censused again in 1987. We were unable to survey again the three easternmost 


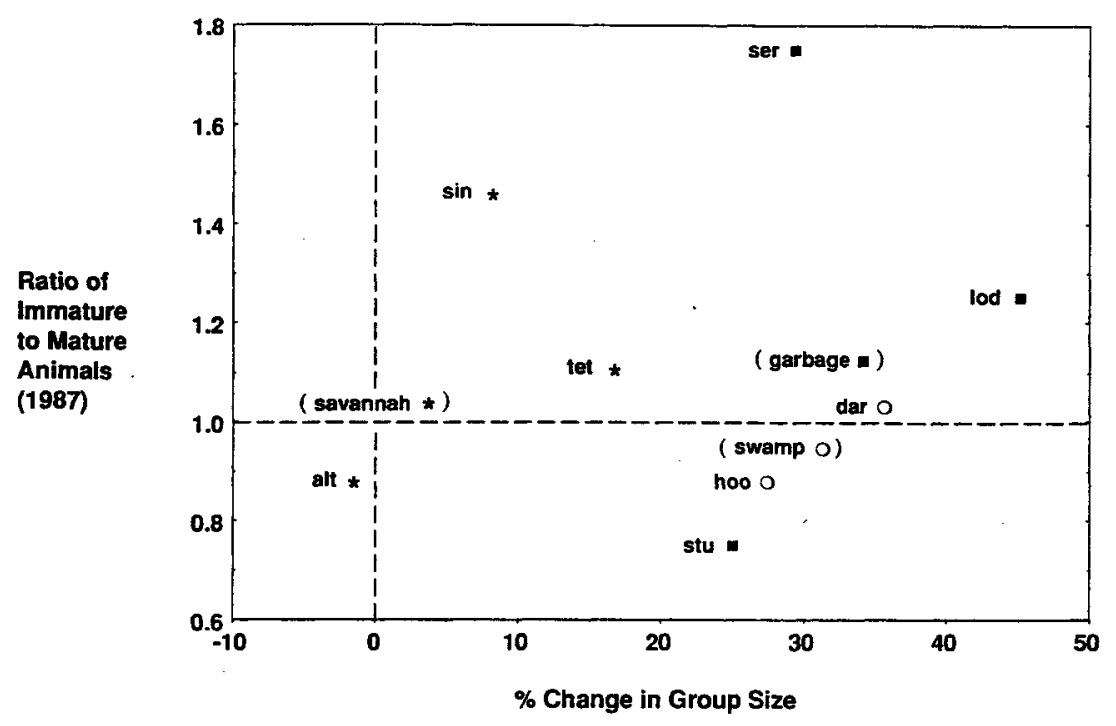

Fig. 3. The relationship of the change in group size from 1984 to 1987 to the ratio of immature to mature animals in 1987. Feeding conditions are indicated as in Fig. 2.

groups, which had been among the largest groups in the population in 1984 and which included both crop-feeding groups.

In 1987, the distribution of anubis baboons was similar to that of 1984. More than $95 \%$ of adults and juveniles of the eight groups censused again in 1987 were yellow-type baboons, and anubis baboons were found in two of the three western groups in the basin. Although no anubis members were in SIN at the time of the 1987 census, anubis males were seen with the group within the 6 months preceding and following the survey.

Nearly all groups censused again in 1987 showed an increase in group size over the 2.5-year period ( $n=8$ groups, $p=0.035$ ); five of those groups increased in size more than $20 \%$. Groups in better feeding conditions showed greater increases in group size (Fig. 3). The three groups that habitually fed on garbage showed an overall increase of $34.2 \%$, and the two groups that ranged primarily around the central swamps increased $31.5 \%$, whereas the three groups that ranged predominantly in dry savannah regions showed only $3.8 \%$ increase in group size.

Although an increase in group size was associated with feeding condition, we could identify no single demographic process that would account for the observed population growth (Fig. 3). The 57 "additional" animals in the recensused portion of the population represented all age/sex classes: 5 adult males, 5 subadult males, 9 or 10 adult females, 30 or 31 juveniles, 
and 7 infants/yearlings. Several groups with the greatest growth showed increases in numbers of immature animals and/or adult females. Increases in the number of adult males were observed only in the two swamp groups.

Although the proportion of immature animals within the population, and particularly within garbage-feeding groups, was higher in 1987 than in 1984 , the proportion of immature animals in 1987 was not significantly different from the proportion of mature animals within the population as a whole, within any feeding condition, or within any group. However, significantly more of the "additional" animals in the population were immature than the expected one-half (ratio $=1.92$ immature per mature animals, $n=57, p=.012$ ). Garbage-feeding groups tended to have large cohorts of infants/yearlings, and large numbers of juveniles were found in swamp groups and a garbage-feeding group.

Growth in garbage-feeding and swamp groups was associated also with increases of adult females. In contrast to the 1984 survey in which females outnumbered males in only one group, two garbage-feeding groups and a swamp group had significantly more adult females than adult males in 1987 (LOD, sex ratio $=2.4$ females per male, $n=17$ adults, $p=0.047$; SER, sex ratio 7.0, $n=8, p=.031$; HOO, sex ratio $=2.1, n=28, p=$ 0.026 ), despite stable or increasing numbers of adult males. In particular, the overall adult sex ratio of garbage-feeding groups increased from 2.0 females per male in 1984 to 2.5 in $1987(n=42, p=.002)$.

To estimate adult replacement under different feeding conditions, we compared, for each of the three primary study groups, the actual number of females that entered each group through maturation relative to the number that left through death, during the time period for which we had longitudinal data. ALT, a savannah group that remained stable in size, had equal numbers of females that matured $(n=12)$ and that died $(n=11)$ over a 7-year period. HOO, a swamp group that increased in size, had twice as many females that matured $(n=13)$ as died $(n=6)$ over a 7-year period. LOD, a garbage-feeding group that increased in size, had three times as many females that matured $(n=3)$ as died $(n=1)$ over a 3-year period.

\section{Male Dispersal Within the Amboseli Basin}

An adult male that disappears may die suddenly within his group or he may leave the group. An emigrating male may then die, live alone for a considerable period, or join another group. In many cases, these events cannot be distinguished with certainty, but for nearly all cases presented below, we are able to rule out death before leaving the group. 


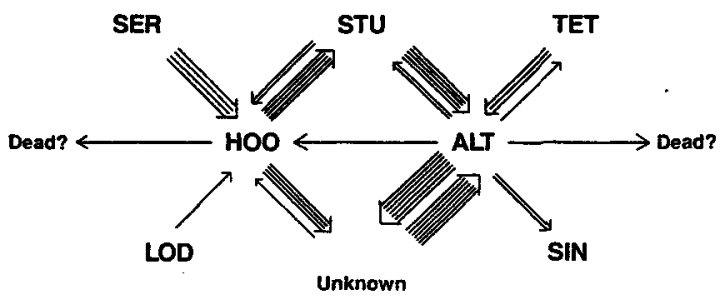

Fig. 4. The direction of migration of males leaving or entering ALT and HOO groups from September 1982 through July 1987, including males of unknown fate or origin. Each line represents one migration event. The home range of ALT overlaps with those of HOO, SIN, STU, and TET; the home range of $H O O$ overlaps with those of ALT, LOD, SER, and STU.

From September 1982 through July 1987, there were 49 migration events involving 37 males to or from two primary study groups, ALT and HOO. Eleven of the 24 departing males (46\%) went to known destinations, and 17 of the 25 immigrants $(68 \%)$ were from known origins. In all cases of known origin or destination, migrants came from or went to an adjacent group (Fig. 4).

Of the 13 males that emigrated to unknown destinations, 2 probably died: a crippled male disappeared on a morning when lions were nearby (recorded by R. and B. Noe) and an old male was last seen alone, injured, and emaciated (recorded by R. S. Mututua and S. Altman). None of the remaining 11 migrant males of unknown destinations were found in either basinwide survey, i.e., the four males that disappeared before the 1984 survey were not located 17 to 97 weeks after their departures; the seven males that disappeared between the 1984 and the 1987 surveys were not located 13 to 117 weeks after their departures.

Solitary males are uncommon but do exist in the Amboseli population. In the 1984 survey, a solitary adult male was observed on a number of occasions to sleep and travel by himself, and he visited the garbage pit at a ranger outpost for several months. He was seen always within the home range of KEL and, in March 1985, joined KEL. We know little about the nature or duration of his solitary period, but we know more about two other males born in primary study groups that became solitary during the interim between censuses. Each male left his natal group at age 8-9 years, remained solitary for 8 months, then joined a group adjacent to his natal group. Each male was seen repeatedly during his period of solitary life, remaining within the range but rarely within the immediate proximity of his natal and destination group. 


\section{DISCUSSION}

The present survey, drawn from a wide geographic area, complemented the more focused, long-term studies of selected groups within the baboon community of the Amboseli basin (Altmann et al., 1981, 1985). In particular, the present survey (1) documented the persistence and extent of the influx of anubis baboons into the predominantly cynocephalus community (Samuels and Altmann, 1986); (2) provided an additional example of the nonrandom dispersal pattern of cercopithecine males (Packer, 1979; Cheney and Seyfarth, 1983); and (3) confirmed the continued stability of the basinwide population (Altmann et al., 1985). The survey also allowed us to identify some characteristics of groups within the community that were demographically more successful.

\section{Gene Flow into and Within the Population}

Since 1982, anubis baboons have remained a small but persistent component of the Amboseli basin population. Baboons that were anubis in appearance were found only in the three groups that range in the southwestern portion of the basin. Anubis members of TET included both males and females, whereas all anubis members of the other groups were male. Because females are the sex that does not disperse, we concluded that TET was an anubis group into which cynocephalus males had immigrated. Our supposition that the anubis community on Mt. Kilimanjaro was the source of the anubis invasion into the basin (Samuels and Altmann, 1986) was supported by more recent observations of TET in the foothills beyond the southwestern edge of the basin. The recent appearance of anubis baboons in Amboseli may result from a shift in the ranging patterns of anubis baboons of the foothills due to expanding agricultural activities on the slopes of Kilimanjaro (Lovatt Smith, 1986, personal observation). Such a shift would facilitate exchange of males between basin and foothill communities. Current genetic studies of the Amboseli baboons, and of baboon populations elsewhere, may assist in the interpretation of the extent of anubis influence within Amboseli.

Patterns of male dispersal within the basin population also affect population structure. Despite extensive searching to determine the dispersal range of male baboons of Amboseli, the only migrant males that we located were those that moved to groups immediately adjacent to their group of origin. Among cercopithecines, movement of males primarily between adjacent groups has been documented also for vervet monkeys (Cheney and Seyfarth, 1983) and anubis baboons (Packer, 1979). Our lack of success in 
locating all emigrating males suggests that males not found in adjacent groups either died or traveled long distances and left the community. Circumstantial evidence indicates that both suppositions are correct: two males disappeared while they were ailing; in addition, a known lone male was found on a waterless plain at the edge of the basin (recorded by R. and B. Noe), more than $20 \mathrm{~km}$ from his group of origin (HOO). Ongoing research focuses on the behavior of male baboons and on patterns of dispersal within the Amboseli community.

\section{Effects of Behavioral Flexibility on Demographic Processes}

The present survey confirmed that the Amboseli baboon population continues to be stable in size and that the stability is basinwide. A dramatic decline in baboon numbers in the 1960 s and early 1970s, followed by stabilization in the mid-1970s, was revealed by demographic analyses based on repeated censuses of the central basin subpopulation (Altmann et al., 1985). The present survey verified that the stability indicated in the geographically limited but longer-term analyses of groups in the central basin is representative of the status of the entire basin community.

The present overall stability of the Amboseli baboon population is surprising in view of dramatic ecological changes ongoing in the Amboseli basin, in particular the continued decline of the fever tree, Acacia xanthophloea, woodland (Western and van Praet, 1973; Altmann, 1977; Western, 1983; Lovatt Smith, 1986). Local populations of several wildlife species have been affected adversely by loss of habitat, including vervet monkeys (Struhsaker, 1973, 1976; Cheney et al., 1988).

The tenacity of the baboons, despite the decline of their preferred fever tree habitat, may result in large part from their behavioral flexibility. Over the past decade, we observed major, though gradual, shifts in the home ranges of several baboon groups in the basin away from areas of fever tree die-offs to new areas where healthy fever tree woodlands remain.

Change of range by other baboon groups has been possible through exploitation of new resources. For example, although baboons in Amboseli typically sleep in fever trees (Altmann and Altmann, 1970), some groups recently began to utilize other tree species for sleeping. On only one occasion (recorded by R. and B. Noe) before 1984 were baboons observed to sleep in trees other than $A$. xanthophloea (Amboseli longitudinal data base, unpublished). By 1987, however, at least three baboon groups were frequently sleeping in $A$. tortillis trees as well, and 15 tortillis sleeping groves had been added to a comprehensive list of more than 110 xanthophloea sleeping groves compiled since the early 1970s (S. Altmann, unpublished 
data). A few groves of another Acacia species and Syzygium guineensis are now used as well.

The success of baboons in diverse ecosystems has been attributed in part to their eclectic feeding habits with respect to natural foods (Norton et al., 1987). Exploitation of human foods is another example of the behavioral flexibility of baboons. Nearly half of the groups in the Amboseli basin have discovered and are coming to rely upon this new resource. Inadvertent provisioning of wildlife with cultivated crops is spreading with the expansion of farmland in the basin. Farms first appeared in Namalog in the early 1980 s and the human population grew rapidly to more than 1000 by 1987 (D. Maitumo, personal communication). Resident wildlife species of Namalog Swamp, including baboons, now supplement their diets with cultivated crops, despite efforts by farmers to eliminate crop-raiding pests that threaten their livelihood.

In addition, as the human population within the park has increased steadily, there has been a corresponding increase in the availability of garbage to baboons and other wildlife. Only a single group of baboons fed on garbage in 1982, while 5 years later, three baboon groups obtained much of their nourishment from discarded human foods. In Amboseli, garbage continues to provide a portion of the diet of many wild animals including baboons, despite limited success of numerous garbage-management schemes.

While the baboon population remained stable overall, certain groups within the population increased in size during the interim between censuses. Increases in group size were associated with better feeding conditions, but we were unable to pinpoint a single demographic process as causal. The maturation of a large cohort of infants born after the 1984 drought may have inflated temporarily the number of immature animals. However, from recent studies of a garbage-feeding group (J. Altmann et $a l$, unpublished data), we now know that in semiprovisioned conditions, youngsters mature more rapidly and females reach sexual maturity at an earlier age and have accelerated reproductive rates, relative to their peers in wild-feeding groups (Fa and Southwick, 1988; Asquith, 1989). Reduced adult mortality and accelerated rates of maturation and reproduction no doubt contributed substantially to the observed growth of groups that had better feeding conditions.

Moreover, accelerated maturational rates may explain biased adult sex ratios that we found in groups in better feeding conditions. Females of LOD mature into the adult class at an earlier age, while male maturation and dispersal from LOD are not comparably accelerated (J. Altmann et al., unpublished data), resulting in a pattern of adult sex ratios skewed toward females. In poor feeding conditions, the converse may be true: for example, 
following severe food and water shortage, the adult sex ratio within a community of chacma baboons shifted to favor males (Hamilton, 1985).

An additional consequence of differential maturational rates is that, for different feeding conditions, age class membership based upon visual criteria, as was used in this survey and others, is more likely to be equivalent to developmental rather than chronological age. Thus estimated ages of immature animals in groups that receive food provisioning may be biased upwards.

\section{Consequences of Food Provisioning}

Availability of predictable, concentrated, high-quality food resources such as garbage and crops is a mixed blessing for baboons and other wildlife. Provisioning that is carefully planned may be employed to enhance conservation efforts (Lyles and Dobson, 1988; Asquith, 1989). More typically, provisioning is inadvertent, and the short-term benefits may be offset in the long run by gradual alterations in behavior, social organization, and demographic structure (Lee et al., 1986; Altmann and Muruthi, 1988; Fa and Southwick, 1988; Asquith, 1989). Such alterations can be life-threatening if, for example, youngsters do not learn how to find and process natural foods or precocious mothers do not learn the skills needed to care for their offspring (Altmann, 1986). Benefits afforded by provisioning are more immediately counteracted when feeding on rich, contaminated, or concentrated foods results in disease or health risks (Wrangham, 1974; Rolland et al., 1985; Sapolsky and Else, 1987) or when the inevitable direct conflict with humans occurs. Baboons that feed on human foods eventually become dangerous to or threaten the lifelihood of the humans with whom they come into contact, and "problem" monkeys are frequently destroyed (Else and Eley, 1985; Lee et al., 1986; but see Strum, 1987).

Behavioral flexibility of baboons has enabled them to adapt to the ongoing ecological shift from Acacia woodland to grassland habitat and to the encroachment of human populations into wildlife habitat. Despite the adaptability of the baboons, the stable status of the Amboseli population may be short-lived. Although some groups in the population appear to be thriving, we suspect that crop-feeding groups are declining, as has occurred in primate populations in other agricultural areas (Southwick et al., 1983). We were unable to reevaluate the status of Amboseli crop-feeding groups because those baboons became unapproachable when farmers began to kill them. Behavioral adaptations of baboons, such as feeding on human foods, that we found to be associated with demographic success in the short term, 
are the very same behaviors that, in the long term, put baboons on a collision course with human development.

\section{ACKNOWLEDGMENTS}

This research is the result of the combined efforts of the Amboseli Baboon Research Project, the Institute of Primate Research (IPR) of the National Museums of Kenya, and the Kenya Wildlife Conservation and Management Department (WCMD), now the Kenya Wildlife Service. We thank J. G. Else, former IPR director, D. M. Sindiyo, former WCMD director, B. Oguya, former warden of Amboseli National Park, and our Amboseli Baboon Project colleagues, S. C. Alberts, P. Muruthi, R. S. Mututua, and V. S. Sikawa. We are grateful to those who shared with us their knowledge of Amboseli and its wildlife, including the people of Namalog; wildlife rangers and tour guides of Amboseli; and P. C. Lee, J. H. Poole, D. Western, and especially J. P. Leboo. We particularly acknowledge the persistent efforts to prevent wildlife from feeding on garbage made by the staff of the Ololarashi-Olgulului Group Ranch Campsite and by K. Lindsay and fellow Amboseli researchers. S. C. Alberts, S. A. Altmann, and P. Muruthi made helpful comments on the manuscript; L. Fitzgerald, K. Mozdzierz, L. Perfect, and C. Saunders helped with figure preparation; and L. Reiter helped with manuscript preparation. The Woods Hole Oceanographic Institution provided facilities for AS during the final manuscript preparation. This research was supported by Grant MH15007, National Geographic, and the Chicago Zoological Society.

\section{REFERENCES}

Altmann, J. (1980). Baboon Mothers and Infants. Harvard University Press, Cambridge.

Altmann, J. (1986). Adolescent pregnancies in non-human primates: An ecological and developmental perspective. In Lancaster, J., and Hamburg, B. (eds.), School-Age Pregnancy and Parenthood. Aldine, Chicago, pp. 247-262.

Altmann, J., and Muruthi, P. (1988). Differences in daily life between semiprovisioned and wild-feeding baboons. Am. J. Primatol. 15:213-221.

Altmann, J., Hausfater, G., and Altmann, S. A. (1981). Physical maturation and age estimates in yellow baboons, Papio cynocephalus, in Amboseli National Park, Kenya. Am. J. Primatol, 1:389-399.

Altmann, J., Hausfater, G., and Altmann, S. A. (1985). Demography of Amboseli baboons, 1963-1983. Am. J. Primatol 8: 113-125.

Altmann, J., Altmann, S. A., and Hausfater, G. (1988). Determinants of reproductive success in yellow baboons. In Clutton-Brock, T. H. (ed.), Reproductive Success, University of Chicago Press, Chicago, pp. 403-418.

Altmann, S. A. (1977). The Acacia Woodland of Amboseli National Park: Current Status and Future Prospects, Report submitted to the Director, Kenya National Parks. 
Altmann, S. A., and Altmann, J. (1970). Baboon Ecology, University of Chicago Press, Chicago. Asquith, P. J. (1989). Provisioning and the study of free-ranging primates: History, effects and prospects. Yearb. Phys. Anthropol. 32: 129-158.

Buettner-Janusch, J. (1966). A problem in evolutionary systematics: Nomenclature and classification of baboons, Genus Papio. Folia Primatol 4: 288-308.

Cheney, D. L., and Seyfarth, R. M. (1983). Nonrandom dispersal in free-ranging vervet monkeys: Social and genetic consequences. Am. Nat. 122(3):392-412.

Cheney, D. L., Seyfarth, R. M., Andelman, S. J., and Lee, P. C. (1988). Reproductive success in vervet monkeys. In Clutton-Brock, T. H. (ed.), Reproductive Success, University of Chicago Press, Chicago, pp. 384-402.

Dittus, W. P. J. (1977). The social regulation of population density and age-sex distribution in the toque macaque. Behaviour 63:281-322.

Else, J., and Eley, D. (1985). Don't feed the monkeys. Swara 8:31-32.

Fa, J. E., and Southwick, C. H. (1988). Ecology and Behavior of Food-enhanced Primate Groups, Monographs in Primatology, Vol. 11, Alan R. Liss, New York.

Goodall, J. (1986). The Chimpanzees of Gombe, Harvard University Press, Cambridge.

Hamilton, W. J., III (1985). Demographic consequences of a food and water shortage to desert chacma baboons, Papio ursinus. Int. J. Primatol. 6(5):451-462.

Harcourt, A. H., Fossey, D., Stewart, K., and Watts, D. P. (1980). Reproduction in wild gorillas and some comparisons with chimpanzees. J. Reprod. Fertil. Suppl. 28:59-70.

Harcourt, A. H. Fossey, D., and Sabatier Pi, J. (1981). Demography of Gorilla gorilla. J. Zool. Lond. 195:215-233.

Hausfater, G., Altmann, J., and Altmann, S. A. (1982). Long-term consistency of dominance relations among female baboons (Papio cynocephalus). Science 217:752-755.

Jolly, C. J., and Brett, F. L. (1973). Genetic markers and baboon biology. J. Med. Primatol. 2:85-99.

Kingdon, J. (1974). East African Mammals, Vol. 1, University of Chicago Press, Chicago.

Lee, P. C., Brennan, E. J., Else, J. G., and Altmann, J. (1986). Ecology and behavior of vervet monkeys in a tourist lodge habitat. In Else, J. G., and Lee, P. C. (eds.), Primate Ecology and Consenvation, Cambridge University Press, Cambridge, pp. 229-235.

Lovatt Smith, D. (1986). Amboseli, Nothing Short of a Miracle, East African Publishing House, Nairobi.

Lyles, A. M., and Dobson, A. P. (1988). Dynamics of provisioned and unprovisioned primate populations. In Fa, J. E., and Southwick, C. H. (eds.), Ecology and Behavior of Food-enhanced Primate Groups, Monographs in Primatology, Vol. 11, Alan R. Liss, New York, pp. 167-198.

Maples, W. R., and McKern, T. W. (1967). A preliminary report on classification of the Kenya baboon. In Vartborg, H. (ed.), The Baboon in Medical Research, Vol. 2, University of Texas Press, Austin, pp. 13-22.

Napier, J. R., and Napier, P. H. (1967). A Handbook of Living Primates, Academic Press, New York, London.

Norton, G. W., Rhine, R. J., Wynn, G. W., and Wynn, R. D. (1987). Baboon diet: A five-year study of stability and variability in the plant feeding and habitat of the yellow baboons (Papio cynocephalus) of Mikumi National Park, Tanzania. Folia Primatol. 48: 78-120.

Packer, C. (1979). Inter-troop transfer and inbreeding avoidance in Papio anubis. Anim. Behav. 27:1-36.

Rolland, R., Hausfater, G., and Levy, S. B. (1985). Antibiotic resistance in wild baboons: Increased prevalence in baboons feeding on human refuse. Appl. Environ. Microbiol. 49(4):791-794.

Samuels, A., and Altmann, J. (1986). Immigration of a Papio anubis male into a group of Papio cynocephalus baboons and evidence for an anubis-cynocephalus hybrid zone in Amboseli, Kenya. Int. J. Primatol. 7(2):131-138.

Sapolsky, R. M., and Else, J. G. (1987). Bovine tuberculosis in a wild baboon population: Epidemiological aspects. J. Med. Primatol. 16:229-235.

Southwick, C. H., and Siddiqi, M. F. (1976). Demographic characteristics of semi-protected rhesus groups in India. Yearb. Phys. Anthropol. 20:242-252. 
Southwick, C. H., and Siddiqi, M. F. (1977). Population dynamics of rhesus monkeys in northern India. In Prince Rainier III and Bourne, G. H. (eds.), Primate Consenvation, Academic Press, New York, pp. 339-362.

Southwick, C. H., Siddiqi, M. F., and Oppenheimer, J. R. (1983). Twenty-year changes in rhesus monkey populations in agricultural areas of northern India. Ecology 64(3):434-439.

Struhsaker, T. T. (1973). A recensus of vervet monkeys in the Masai-Amboseli Game Reserve, Kenya. Ecology 54:930-932.

Struhsaker, T. T. (1976). A further decline in numbers of Amboseli vervet monkeys. Biotropica 8:211-214.

Strum, S. C. (1987). Almost Human, Random House, New York.

Van Citters, R. L., Smith, O. A., Franklin, D. L., Kemper, W. S., and Watson, N. W. (1967). Radio telemetry of blood flow and blood pressure in feral baboons: A preliminary report. In Vartborg, H. (ed.), The Baboon in Medical Research, Vol. 2, University of Texas Press, Austin, pp. 473-492.

Walters, J. (1980). Interventions and the development of dominance relationships of female baboons. Folia Primatol. 34:61-89.

Western, D. (1973). The Structure, Dynamics, and Changes of the Amboseli Ecosystem, Ph.D. thesis, University of Nairobi.

Western, D. (1983). A Wildlife Guide and a Natural History of Amboseli, Author, Nairobi.

Western, D., and Sindiyo, D. M. (1972). The status of the Amboseli rhino population. E. Afr. Wildl. J. 10: 43-57.

Western, D., and van Praet, C. (1973). Cyclical changes in the habitat and climate of an east African ecosystem. Nature 241:104-106.

Wrangham, R. W. (1974). Artificial feeding of chimpanzees and baboons in their natural habitat. Anim. Behav. 22:83-93. 